\title{
EVALUASI KEPUASAN PELANGGAN DI POLTEKKES KEMENKES PALANGKA RAYA
} TAHUN 2017

\author{
${ }^{1}$ Gad Datak, ${ }^{2}$ Lamia Diang Mahalia, ${ }^{3}$ Riyanti \\ 1,2,3 Politeknik Kesehatan Kementerian Kesehatan Palangka Raya
}

\begin{abstract}
ABSTRAK
Kualitas layanan pendidikan dapat diamati dengan cara mengukur sejauh mana institusi pendidikan sebagai pemberi layanan dapat memberikan jaminan mutu kepada penerima layanan. Pemerintah melalui Kepmenpan Nomor KEP/25/M.PAN/2/2004 telah membuat pedoman penilaian kepuasan pelanggan bagi setiap institusi pelayanan termasuk institusi pendidikan. Poltekkes Kemenkes Palangka Raya sebagai institusi yang memberikan layanan pendidikan perlu untuk mengukur kepuasan pelanggan. Penelitian ini bertujuan untuk mengetahui kepuasan pelanggan terhadap layanan di Poltekkes Kemenkes Palangka Raya. Metode yang digunakan adalah survey dengan alat bantu kuesioner. Responden dalam penelitian inisebayak 437 orang yang terdiri atas mahasiswa, dosen, tenaga kependidikan, orang tua, alumni, dan stakeholder. Hasil penelitian menunjukkan bahwa nilai indeks kepuasan mahasiswa, dosen, danorang tua masuk dalam kategori baik, dan kategori sangat baik untuk nilai indeks kepuasan tenaga kependidikan, alumni dan stakeholder. Dengan demikian dapat disimpulkan bahwa secara umum pelayanan di Poltekkes Kemenkes Palangka Raya dapat memberikan kepuasan kepada mahasiswa, dosen, tenaga kependidikan, orang tua, alumni, dan stakeholder.
\end{abstract}

Kata kunci: indeks kepuasanpelanggan, layanan pendidikan, mutu layanan pendidikan

\begin{abstract}
The quality of education service can observe with how the institution give a quality asurance. The goverment pass through Kepmenpan No : KEP/25/M.PAN/2/2004 have made guedeline to assess of costumers satisfaction for every institution belonging to educational institution. Health Polytechnic Palangka Raya as an educational institution have given education serve need to measure about costumers satisfaction.Survey have been a method on this research with a quesioner as the instrument. 437 people have been a responden on this research consists of student, lecturer, staff, parent, alumni and stakeholder. The result of the research have shownstudent,lecturer, and parent satisfactionindex value belonging to a good actual performance and very good for staff, alumni, and stakeholder. Thereby, it is generally that educational services on Health Polytechnic Palangka Raya was gave satisfaction to thestudent, lecturer, staff, parent, alumni and stakeholder.
\end{abstract}

Keyword : costumers satisfaction index, educational services, quality service performance 


\section{PENDAHULUAN}

Paradigma baru penyelenggaraan pendidikan dewasa ini dituntut adanya pengelolaan layanan pendidikan yang dapat memuaskan pelanggan. Kepuasan pelanggan pendidikan akan berpengaruh besar terhadap keberlangsungan dan maju mundurnya suatu lembaga pendidikan. Lembaga pendidikan bermutu yang dapat memuaskan pelanggan akan diburu masyarakat meskipun terpencil dan mahal. Sebaliknya, lembaga pendidikan yang mengecewakan pelanggan akan ditinggalkan masyarakat ${ }^{1}$.

Pendidikan yang bermutu dapat diindikasikan sebagailayanan pendidikan yang mampu menghasilkan output pendidikan yang sesuai dengantuntutan masyarakat. Paradigma mutupendidikan yang berorientasi pada klien didefinisikan sebagai ukuran sejauh manaprogram dan hasil keluaran sekolah (perguruan tinggi) tersebut telah memenuhi kebutuhan dan harapanklien. Ada tiga hal yang perlu dipahami oleh lembaga penyelenggarapendidikan untuk memenuhi kebutuhan dan harapan klien, yaitu: (1) apa kebutuhanklien; (2) bagaimana mengetahui kebutuhan klien; dan (3) apa yang membuat merekapuas.Berdasarkan uraian tersebut maka dapat disimpulkan bahwa indikator kualitaspelayanan pendidikan yang bermutu terutama harus diorientasikan padakebutuhan klien atau pihak-pihak penerima layanan tersebut ${ }^{2}$.
Kementerian

Pendayagunaan

Aparatur Negara telah mengatur pengukuran kualitas layanan secara komprehensif melalui Surat Keputusan Menteri PAN Nomor KEP/25/M.PAN/2/2004 tentang pedoman umum penyusunan indeks kepuasan masyarakat di unit pelayanan instansi pemerintah.

Politeknik Kesehatan Kementerian Kesehatan Palangka Raya berdasarkan Surat Keputusan Kepala Badan PPSDM Kesehatan RI tahun 2001 merupakan salah satu institusi pendidikan kesehatan yang dipercaya untuk melaksanakan tugas tri dharma perguruan tinggi guna membantu Kementerian Kesehatan dalam hal penyedia tenaga kesehatan. Agar visi Poltekkes Kemenkes Palangka Raya dalam menghasilkan tenaga kesehatan yang professional, kompetitif dan bermartabat dapat terwujud, maka haruslah didukung oleh kualitas layanan yang memuaskan.

Penelitian terkait kepuasan pelanggan di Poltekkes Kemenkes Palangka Raya sudah pernah dilakukan pada tahun 2014, namun lingkup penelitian tersebut sebatas melihat kepuasan layanan pendidikan dari mahasiswa Poltekkes Kemenkes Palangka Raya saja ${ }^{3}$. Oleh karena itu, peneliti tertarik untuk melakukan penelitian kepuasan pelanggan pada lingkup yang lebih luas yaitu pihak internal dan eksternal meliputi mahasiswa, dosen, 
Gad Datak, Lamia Diang Mahalia dan Riyanti

tenaga kependidikan, orang tua, alumni, swasta di kota Palangka Raya. Pelanggan dan stakeholder.

\section{METODE PENELITIAN}

Penelitian ini merupakan jenis penelitian survey dengan alat bantu kuesioner yang dibuat berdasarkan Pedoman Penilaian Indeks Kepuasan Masyarakat yang dikeluarkan oleh Menteri PAN tahun $2004^{4}$. Survey dilaksanakan di lingkungan Poltekkes Kemenkes Palangka Raya dan beberapa instansi kesehatan di Palangka raya seperti rumah sakit pemerintah, rumah sakit swasta, klinik, dan puskesmas sejak tanggal 15 sampai 19 Mei 2017. Responden dalam penelitian ini meliputi mahasiswa, dosen, tenaga kependidikan, orang tua, alumni, dan stakeholder.Pengumpulan data dilakukan dengan cara pengisian kuesioner oleh responden.Pengolahan data menggunakan perangkat lunak SPSS versi 20 dan Microsoft excel 2007. Analisis data dilakukan secara deskriptif yang disajikan dalam bentuk persentase dan grafikal.

\section{HASIL DAN PEMBAHASAN}

Penelitian ini dimulai sejak awal bulan Mei 2017. Penyebaran kuesioner dilakukan di Poltekkes Kemenkes Palangka Raya dan di luar lingkup Poltekkes Kemenkes Palangka Raya yaitu unit, sub bagian, jurusan keperawatan, jurusan kebidanan, jurusan gizi, beberapa instansi kesehatan pemerintah dan

yang dimaksud dalam survey ini adalah mahasiswa, orang tua mahasiswa, pegawai Poltekkes Kemenkes Palangka Raya (tenaga pendidik dan tenaga kependidikan), alumni, dan stakeholder. Dari 530 eksemplar kuesioner yang telah disebarkan, sejumlah kuesioner yang kembali dan telah terisi sebanyak 437 eksemplar. Rincian sebaran responden dapat dilihat pada Tabel 1.

Tabel 1. Sebaran responden berdasarkan kategori

\begin{tabular}{clccc}
\hline No & $\begin{array}{l}\text { Respon } \\
\text { den }\end{array}$ & Target & $\begin{array}{c}\text { Ter- } \\
\text { kum }\end{array}$ & $\%$ \\
& & & $\begin{array}{c}\text { pul } \\
134\end{array}$ & $91,78 \%$ \\
\hline 1 & Mahasis & 146 & 130 \\
& wa & & & \\
\hline 2 & Orang & 146 & 130 & $89,04 \%$ \\
& tua & & & \\
\hline 3 & Dosen & 40 & 35 & $87,5 \%$ \\
\hline 4 & $\begin{array}{l}\text { Tenaga } \\
\end{array}$ & 68 & 44 & $64,70 \%$ \\
& $\begin{array}{l}\text { Kependi } \\
\text { dikan }\end{array}$ & & & \\
\hline 5 & Alumni & 65 & 53 & $81,54 \%$ \\
\hline 6 & Stakehol & 65 & 41 & $63,07 \%$ \\
& der & & & \\
\hline
\end{tabular}

Kuesioner survey kepuasan pelanggan disebarkan kepada mahasiswa, dosen, tenaga kependidikan, orang tua,alumni dan stakeholder. Adapan unsur yang dinilai adalah kepuasan mahasiswa terhadap pelayanan di program studi/jurusan, ADAK, laboratorium dan perpustakaan. Selain itu dinilai juga kepuasan orang tua, dosen, tenaga kependidikan, alumni dan 
stakeholder terhadap institusi pendidikan tinggi Poltekkes Kemenkes Palangka Raya. Kategori penilaian menggunakan standar yang telah ada dalam Kepmenpan Nomor.

Kep/25/M.PAN/2/2004, Rangkuman hasil survey kepuasan pelanggan dapat dilihat pada Tabel 2 .

Tabel 2. Rangkuman hasil survey Kepuasan Pelanggan

\begin{tabular}{|c|c|c|c|}
\hline No & $\begin{array}{c}\text { Respon } \\
\text { den }\end{array}$ & $\begin{array}{c}\text { Unsur } \\
\text { Penilaian }\end{array}$ & Hasil \\
\hline 1 & $\begin{array}{l}\text { Mahasis } \\
\text { wa }\end{array}$ & $\begin{array}{l}\text { Kepuasan } \\
\text { mahasiswa } \\
\text { terhadap } \\
\text { pelayanan di } \\
\text { Prodi/Jurusan, } \\
\text { ADAK, Lab \& } \\
\text { Perpustakaan }\end{array}$ & Baik \\
\hline 2 & $\begin{array}{l}\text { Orang } \\
\text { tua }\end{array}$ & $\begin{array}{l}\text { Kepuasan } \\
\text { terhadap } \\
\text { Poltekkes } \\
\text { Kemenkes } \\
\text { Palangka Raya }\end{array}$ & Baik \\
\hline 3 & Dosen & $\begin{array}{l}\text { Kepuasan } \\
\text { terhadap } \\
\text { Poltekkes } \\
\text { Kemenkes } \\
\text { Palangka Raya }\end{array}$ & Baik \\
\hline 4 & $\begin{array}{l}\text { Tenaga } \\
\text { Kependi } \\
\text { dikan }\end{array}$ & $\begin{array}{l}\text { Kepuasan } \\
\text { terhadap } \\
\text { Poltekkes } \\
\text { Kemenkes } \\
\text { Palangka Raya }\end{array}$ & $\begin{array}{c}\text { Sangat } \\
\text { baik }\end{array}$ \\
\hline 5 & Alumni & $\begin{array}{l}\text { Kepuasan } \\
\text { terhadap } \\
\text { Poltekkes } \\
\text { Kemenkes } \\
\text { Palangka Raya }\end{array}$ & $\begin{array}{c}\text { Sangat } \\
\text { baik }\end{array}$ \\
\hline 6 & $\begin{array}{l}\text { Stake- } \\
\text { holder }\end{array}$ & $\begin{array}{l}\text { Kepuasan } \\
\text { terhadap } \\
\text { Poltekkes } \\
\text { Kemenkes } \\
\text { Palangka Raya }\end{array}$ & $\begin{array}{c}\text { Sangat } \\
\text { baik }\end{array}$ \\
\hline
\end{tabular}

\section{Indeks Kepuasan Mahasiswa}

Untuk menghitung nilai indeks kepuasan mahasiswa, dibutuhkan nilai persepsi kepuasan per unsur layanan pendidikan. Terdapat 14 unsur layanan pendidikan yang ada dalam pedoman dan telah dimodifikasi sehingga berkaitan langsung dengan layanan pendidikan yang telah dilaksanakan oleh Politeknik Kesehatan Kementerian Kesehatan Palangka Raya. Nilai kepuasan mahasiswa dapat dilihat pada Tabel 3.

Tabel 3. Hasil Survey Kepuasan

\begin{tabular}{|c|c|c|c|c|}
\hline \multicolumn{5}{|c|}{ Mahasiswa } \\
\hline No & Lokasi & $\begin{array}{c}\text { Nilai } \\
\text { Indeks } \\
\text { Kepua } \\
\text { san }\end{array}$ & $\begin{array}{l}\text { Nilai } \\
\text { Kon- } \\
\text { versi }\end{array}$ & $\begin{array}{l}\text { Mutu } \\
\text { Pela- } \\
\text { yanan }\end{array}$ \\
\hline 1 & $\begin{array}{l}\text { Prodi/Ju } \\
\text { rusan }\end{array}$ & 3,12 & 78,23 & B \\
\hline 2 & ADAK & 3,00 & 75,81 & B \\
\hline 3 & $\begin{array}{l}\text { Perpus- } \\
\text { takaan }\end{array}$ & 3,11 & 77,82 & $B$ \\
\hline 4 & $\begin{array}{l}\text { Labora- } \\
\text { torium }\end{array}$ & 3,09 & 77,33 & B \\
\hline
\end{tabular}
disimpulkan bahwa kinerja unit pelayanan program studi/jurusan, ADAK, perpustakaan dan laboratorium kepada mahasiswa masuk dalam kategori baik.

\section{Indeks Kepuasan Dosen}

Survei kepuasan dosen terhadap layanan Poltekkes Kemenkes Palangka Raya disebarkan di 6 program studi di Poltekkes Kemenkes Palangka Raya yaitu program studi DIII dan DIV Keperawatan, Kebidanan, dan Gizi. Nilai indeks 
Gad Datak, Lamia Diang Mahalia, dan Riyanti

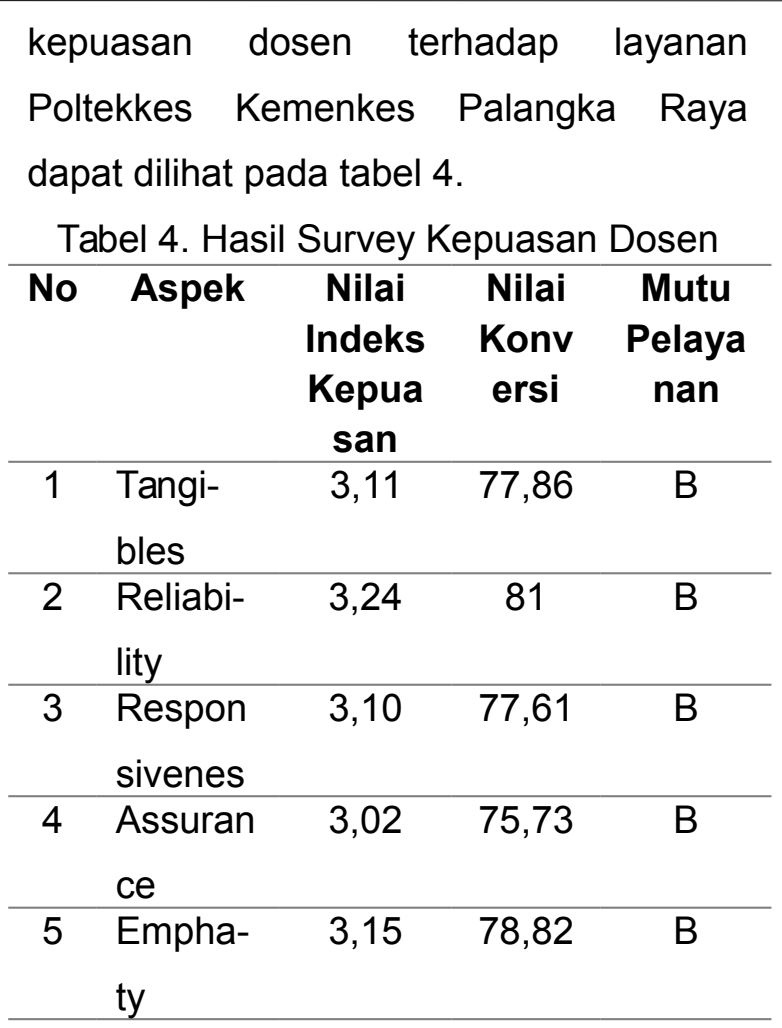

Berdasarkan Tabel 4, dapat disimpulkan bahwa kinerja pelayanan Poltekkes Kemenkes Palangka Raya terhadap dosen masuk dalam kategori baik.

\section{Indeks Kepuasan Tenaga Kependidikan}

Survei kepuasan tenaga kependidikan terhadap layanan Poltekkes Kemenkes Palangka Raya disebarkan di Rektorat dan di 6 program studi Poltekkes Kemenkes Palangka Raya yaitu program studi DIII dan DIV Keperawatan, Kebidanan, dan Gizi. Kuesioner dibagian kepada tenaga kependidikan yang berstatus PNS maupun tenaga kontrak.Nilai indeks kepuasan tenaga kependidikan terhadap layanan Poltekkes Kemenkes Palangka Rayadapat dilihat pada tabel5.
Tabel 5. Hasil Survey Kepuasan Tenaga Kependidikan

\begin{tabular}{clccc}
\hline No & Aspek & $\begin{array}{c}\text { Nilai } \\
\text { Indeks } \\
\text { Kepua } \\
\text { san }\end{array}$ & $\begin{array}{c}\text { Nilai } \\
\text { Kon- } \\
\text { versi }\end{array}$ & $\begin{array}{c}\text { Mutu } \\
\text { Pelaya } \\
\text { nan }\end{array}$ \\
\hline 1 & $\begin{array}{l}\text { Tangi- } \\
\text { bles }\end{array}$ & 3,34 & 86,66 & $\mathrm{~A}$ \\
\hline 2 & $\begin{array}{l}\text { Reliabi- } \\
\text { lity }\end{array}$ & 3,57 & 89,43 & $\mathrm{~A}$ \\
\hline 3 & $\begin{array}{l}\text { Respon } \\
\text { sivenes }\end{array}$ & 3,47 & 86,84 & $\mathrm{~A}$ \\
\hline 4 & $\begin{array}{l}\text { Assuran } \\
\text { ce }\end{array}$ & 3,46 & 86,56 & $\mathrm{~A}$ \\
\hline 5 & $\begin{array}{l}\text { Empha- } \\
\text { ty }\end{array}$ & & & \\
\hline & Berdasarkan $\quad$ Tabel 5, & dapat
\end{tabular}
disimpulkan bahwa kinerja pelayanan Poltekkes Kemenkes Palangka Raya terhadap tenaga kependidikan masuk dalam kategori sangat baik.

Indeks Kepuasan Orang Tua Mahasiswa, Alumni, dan Stakeholder Kuesioner survey kepuasan orang tua disebarkan kepada orang tua mahasiswa program studi DIII dan DIV Keperawatan, Kebidanan dan Gizi yang sedang menjalani perkuliahan pada semester 4. Alasan kuesioner tersebut disebarkan kepada orang tua mahasiswa semester 4 karena orang tua tersebut dianggap telah lama dan banyak terpapar oleh layanan dari Poltekkes Kemenkes Palangka Raya.

Kuesioner survey kepuasan untuk alumni dan stakeholder disebarkan ke berbagai instansi kesehatan di kota Palangka Raya baik pemerintah maupun 
swasta seperti Dinas Kesehatan Provinsi, Rumah Sakit Umum Daerah, puskesmas, dan rumah sakit swasta.Nilai indeks kepuasan dosen terhadap layanan Poltekkes Kemenkes Palangka Raya dapat dilihat pada tabel 6 .

Tabel 6. Hasil Survey Kepuasan Orang Tua, Alumni, dan Stakeholder

\begin{tabular}{clccc}
\hline No & $\begin{array}{c}\text { Respon } \\
\text { den }\end{array}$ & $\begin{array}{c}\text { Nilai } \\
\text { Indeks } \\
\text { Kepua } \\
\text { san }\end{array}$ & $\begin{array}{c}\text { Nilai } \\
\text { Kon- } \\
\text { versi }\end{array}$ & $\begin{array}{c}\text { Mutu } \\
\text { Pelaya } \\
\text { nan }\end{array}$ \\
\hline 1 & Orang & 2,92 & 73,01 & $\mathrm{~B}$ \\
& Tua & & & \\
\hline 2 & Alumni & 3,52 & 88,06 & $\mathrm{~A}$ \\
\hline 3 & $\begin{array}{l}\text { Stake- } \\
\text { holder }\end{array}$ & 3,60 & 90,06 & $\mathrm{~A}$ \\
& & & \\
\hline \multicolumn{4}{l}{ Berdasarkan Tabel 6,} & dapat
\end{tabular}

disimpulkan bahwa nilai kinerja pelayanan Poltekkes Kemenkes Palangka Raya terhadap orang tua mahasiswa masuk dalam kategori baik, dan kategori sangat baik untuk penilaian dari alumni dan stakeholder.

\section{KESIMPULAN}

Nilai indeks kepuasan mahasiswa, dosen, dan orang tua mahasiswa terhadap layanan Poltekkes Kemenkes palangka Raya termasuk dalam kategori mutu B dengan kinerja Baik. Untuk Nilai indeks kepuasan tenaga kependidikan, alumni, dan stakeholder termasuk dalam kategori mutu A dengan kinerja Sangat
Baik. Dari nilai indeks kepuasan yang didapat tersebut dapat disimpulkan bahwa secara umum pelayanan di Poltekkes Kemenkes Palangka Raya dapat memberikan kepuasan baik untuk pihak internal maupun eksternal.

\section{DAFTAR PUSTAKA}

1. Cahir. Analisis Kepuasan Pelanggan Pendidikan, Studi Kasus di SMP 2 Negeri Brebes. Tesis Program Studi Manajemen Pendidikan, Program Pascasarjana Universitas negeri Semarang, 2007.

2. Jaedun A. Survei Tingkat Kepuasan Konsumen Terhadap Kualitas Pelayanan Publik Bidang Pendidikan di Daerah Istimewa Yogyakarta, 2005.

3. Kusfriyadi, Mars Khendra, Nang Randu Utama, dan Lamia Diang Mahalia. Analisis Kepuasan Mahasiswa Terhadap Layanan Pendidikan di Politeknik Kesehatan Kementerian Kesehatan Palangka Raya. Jurnal Forum Kesehatan Volume V Nomor 9. 2015. 57-63.

4. Kepmenpan Nomor : KEP/25/M.PAN/2/ 2004 tentang pedoman umum penyusunan Indeks Kepuasan Masyarakat di unit pelayanan instansi Pemerintah. 2004. 